\title{
Representações sociais da ressocialização através da Educação: a prisão pode constituir-se em espaço educativo?
}

\author{
Social representations of resocialization through Education: can \\ prison become an educational space?
}

Eloiza da Silva Gomes de Oliveira Universidade do Estado do Rio de Janeiro (UERJ) eloizagomes@hotmail.com

Ronaldo Silva Melo Universidade do Estado do Rio de Janeiro (UERJ) ronaldosilvamelo77@gmail.com

\begin{abstract}
Resumo: Este artigo deriva de pesquisa realizada com 80 sujeitos, em dois presídios masculinos do Rio de Janeiro, com o objetivo de identificar representações sociais da ressocialização por meio da educação. Apresentamos aspectos relacionados à percepção da escola e a uma representação social que emergiu na análise dos dados coletados: a de "enquadramento", uma série de atitudes e pensamentos que permitem a sobrevivência no interior do presídio. Concluímos afirmando três necessidades imperativas: a construção de uma concepção de educação prisional não como benesse, mas como direito cidadão; o investimento material e humano nos espaços educativos situados em ambiente prisional; e a existência de uma verdadeira escola de ressocialização. Esta escola não pode ser representada como derivada do "enquadramento" dos presidiários, mas atuar para o mundo externo e promover a constituição de redes de apoio no contexto "extra muros", contemplando também as familias dos presidiários.
\end{abstract}

Palavras-chave: Educação prisional. Ressocialização. Representações sociais.

Abstract: This article derives from a research carried out with 80 subjects, in two male prisons in Rio de Janeiro, with the objective of identifying social representations of resocialization through education. We present aspects related to the perception of the school and to a social representation that emerged in the analysis of the collected data: that of "framework", a series of attitudes and thoughts that allow survival inside the prison. We conclude by stating three imperative needs: the construction of a concept of prison education not as a benefit, but as a citizen right; material and human investment in educational spaces located in a prison environment; and the existence of a real school of resocialization. This school cannot be represented as derived from the "framework" of prisoners, but act for the outside world and promote the creation of support networks in the context "outside the walls", also contemplating the families of prisoners.

Key-words: Prison education. Resocialization.Social representations. 


\section{Sistema Prisional e Educação - alguns dados do Estado do Rio de Janeiro}

A população carcerária do Brasil, segundo o Levantamento Nacional de Informações Penitenciárias (INFOPEN) divulgado em 2019, com atualização de dados de 2017mostra que o total de presos no Brasil passou de 698 mil, no fim de 2015, para 726 mil em junho de 2017 ultrapassando, pela primeira vez na história, a marca de 700 mil pessoas privadas de liberdade. Com isso, houve um aumento da ordem de 707\% em relação ao total registrado no início da década de 1990.

Em relação ao número total de vagas, o documento aponta um déficit total de 303.112 mil, constituindo uma taxa de ocupação de 171,62\% em instituições penitenciárias superlotadas e em péssimas condições de subsistência.

Dessa população prisional, o Rio de Janeiro é a terceira Unidade da Federação com maior número de presos, representando 7,25\% do total, ou mais de 51.000 pessoas, ficando atrás apenas de São Paulo e de Minas Gerais. Esse número representa uma taxa de aprisionamento de 315,16 pessoas presas para cada 100 mil habitantes.

Tomada como legislação referencial, a Constituição da República Federativa do Brasil de 1988, em seu Artigo 205, garante a todos os cidadãos deste país o direito à educação, destacando que educar é dever da família e do Estado e deve visar ao desenvolvimento da pessoa, preparo para a cidadania e mercado de trabalho.

A Lei N N $^{\text {7.210, de }} 11$ de julho de 1984 (Lei de Execução Penal - LEP) instituiu como obrigatório o Ensino Fundamental e o Ensino Profissionalizante, em nível de iniciação ou aperfeiçoamento, para os sujeitos privados de liberdade, e atualmente está em vigor a Lei nº 12.433 , de 29 de junho de 2011, que estabelece uma correlação entre a educação formal e a remição de pena. O estado do Rio de Janeiro é pioneiro no que diz respeito à oferta de educação no sistema penitenciário, sendo referência em educação carcerária.

Desde 1967, ininterruptamente, o Estado do Rio de Janeiro oferece educação aos indivíduos privados de liberdade, preconizando o direito ao acesso, permanência e à formação do cidadão como garantia do desenvolvimento da capacidade de aprender e de se relacionar no meio social e político, estabelecendo, como princípio, a igualdade de condições para o acesso e permanência na escola. O eixo educação nas Unidades Escolares que existem dentro do Sistema Penitenciário do Estado do Rio de Janeiro deve dinamizar as ações pedagógicas, estimular o 
aprendizado, a formação humana, a troca de informações e propiciar condições adequadas aos cidadãos privados de liberdade para a apropriação e produção do conhecimento, visando seu retorno ao convívio social em igualdade aos demais cidadãos daquele Estado, garantindo aos mesmos a dignidade e os direitos sociais, o que não significa constituir privilégios.

Ilustra o que dissemos a elaboração do Plano Estadual de Educação em Prisão (PEEP), que começou ser discutido no ano de 2010 e, após os debates, foi enviado para o Ministério da Justiça e o Ministério da Educação para ser revisado. Retornou da esfera federal e foi pedido à Secretaria de Estado de Educação do Rio de Janeiro que fizesse uma nova revisão e o publicasse infelizmente, mesmo passando por todas essas instâncias, o Plano ainda não foi publicado até a presente data.

Os dados do Sistema Penitenciário do Rio de Janeiro (SIPEN,2018) indicam números preocupantes em relação à escolaridade dos presos. O estudo mostra que, do total de 51.504 presos, quase 61\% têm apenas o Ensino Fundamental incompleto, enquanto 8,59\%completaram o Ensino Fundamental. Pouco mais de 6\% possuem o Ensino Médio completo e quase 7,5\% incompleto. Observa-se, portanto, que há uma grande demanda relativa à escolarização dentro do ambiente de privação de liberdade.

A Secretaria de Estado de Educação do Rio de Janeiro (SEEDUC/RJ), conforme visto anteriormente, atende uma parte desses presos ofertando a Educação Básica em suas escolas estaduais, com 3.637 internos matriculados.

O Sistema Penitenciário do Estado do Rio de Janeiro possui 19 Espaços Educacionais e 4 salas de extensão dentro de 23 Unidades Prisionais. São 19 Colégios Estaduais, pertencentes à Rede da SEEDUC, que oferecem o Ensino Fundamental e o Ensino Médio na modalidade presencial.

Ao confrontar a população prisional do Rio de Janeiro com o percentual de presos sem a conclusão da Educação Básica, que constituem 82,48\% dessa população, e o reduzido número de matrículas nas escolas, 3.637, notamos que há sérios problemas que precisam ser analisados e enfrentados.

Ao pensarmos que parte desse grupo deve ou deveria retornar ao convívio social mais bem preparado para o mundo do que quando adentrou o cárcere, fazem-se necessárias ações dos variados entes federativos buscando a ressocialização e a reabilitação dessa população.

\section{A Teoria das Representações Sociais como fundamentação para a pesquisa}


A escola francesa das representações sociais, tendo Serge Moscovici como um dos seus principais autores, a apresenta como uma forma específica de conhecimento, que interfere nos comportamentos e nos processos comunicacionais entre os seres humanos. Segundo o autor, "elas constituem uma organização psicológica, uma forma de conhecimento particular de nossa sociedade e irredutível a qualquer outra" (MOSCOVICI, 1978, p. 46).

As representações indicam atitudes e valores dos grupos, em uma função que Abric (1998, p.29) chamou de identitária: situar os indivíduos e os grupos no "campo social", elaborando o que podemos chamar de identidade grupal, Têm vertentes cognitivas, simbólicas, afetivas e avaliativas que se expressam, de forma bastante polissêmica, através das várias formas de linguagem.

O processo de construção de uma representação social contempla, obrigatoriamente, um objeto situado em um contexto social e um sujeito que representa esse objeto junto com outros sujeitos. No dizer de Moscovici (1988, p.213) a teoria citada "proporciona (...) uma visão de comunicação e do pensamento cotidiano no mundo de hoje...”.

As representações possuem, ainda, um nexo forte com o coletivo, e a preocupação com a clareza do termo "sociais", que as completa, é expressa por Denise Jodelet:

[...] o conceito de Representação Social designa uma forma específica de conhecimento, o saber do senso comum, cujos conteúdos manifestam a produção de processos generativos e funcionais socialmente marcados. Mais amplamente, designa uma forma de pensamento social. [...] apresenta características específicas no plano da organização dos conteúdos, das operações mentais e da lógica (1984, p. 361-2).

Para a autora as representações sociais dizem respeito à maneira como os sujeitos sociais apreendem os acontecimentos da vida cotidiana, as informações do contexto, as relações intersubjetivas. Dizem respeito aos conhecimentos que são constituídos a partir de nossa experiência, das informações e saberes, dos modelos culturais transmitidos por tradição, pela educação e pelos meios de comunicação, e principalmente pelo compartilhamento. Elas referemse ao modo do indivíduo e do grupo pensar e interpretar o cotidiano, constituindo-se como um conjunto de imagens e ideias e dotado de um sistema de referência que permite ao grupo social interpretar o cotidiano e atribuir sentido aos acontecimentos sociais.

O estudo das representações sociais pode ser efetivado por três vias teóricas: sociogenética, estrutural e sociodinâmica. A abordagem sociogenética enfatiza os "processos de construção das representações sociais"; a estrutural "descreve a sua estruturação interna"; e a sociodinâmica "se concentra em suas relações com as inserções sociais dos indivíduos" (DECHAMPS e MOLINER, 
2009, p. 125). Na pesquisa realizadaforam estudadas as representações sociais dos indivíduos aprisionados sobre a ressocialização e a educação sob a abordagem estrutural, através das observações realizadas e dos questionários utilizados.

\section{A trajetória da pesquisa realizada}

A coleta de dados foi feita através de questionários e, como território da pesquisa, utilizamos duas escolas de presídios masculinos, componentes da rede de escolas prisionais do Rio de Janeiro, mediante autorização do diretor das Unidades Prisionais e da Diretoria Especial de Escolas Prisionais e Socioeducativas.

Os sujeitos receberam os questionários com as instruções para o autopreenchimento e a garantia do anonimato. $O$ entrevistador não conferiu nenhuma orientação adicional durante a aplicação do questionário. Foram aplicados 80 questionários a indivíduos do sexo masculino que cumprem penas variadas nestes dois presídios de segurança máxima.

O questionário foi constituído de perguntas objetivas com a linguagem adaptada para facilitar a compreensão, isto significou a utilização de termos de uso corrente no cotidiano do presídio, com a finalidade de permitir a compreensão e o preenchimento.

As questões foram organizadas de acordo com o objetivo da pesquisa, de identificar as representações sociais da ressocialização pela escola pelos presidiários.

O primeiro bloco de questões foi estruturado para identificação dos sujeitos: por idade, cor, escolaridade e tempo de permanência na escola e no presídio. Desconsideramos nesta identificação a tipificação do crime cometido, por considerarmos que esta variável não era necessária para o objetivo da pesquisa e obrigaria a constituição de correlações complexas que não corresponderiam a um estudo, pioneiro como este, no âmbito das representações sociais com esta população alvo.

O segundo bloco de questões relacionou-se às motivações da permanência ou da frequência em escola no presídio e os benefícios diretos que a escola poderia apresentar para o processo de ressocialização.

O terceiro bloco abordou os benefícios correlatos "produzidos" com a frequência e a permanência em escola no presídio. As questões foram produzidas com base nas restrições estabelecidas no presídio e que a frequência ou permanência na escola poderia flexibilizar, ou suspender temporariamente. Neste bloco de questões foram abordadas restrições ao movimento, à alimentação, à comunicação entre os presos e à comunicação com o "mundo externo". 
O quarto bloco de questões foi organizado com a intenção de avaliar a escola, as condições materiais das mesmas, o cumprimento das finalidades por elas propostas e as práticas pedagógicas utilizadas.

O quinto bloco de questões abordou o comportamento na escola e o sexto e último foi relacionado a uma hierarquização de qual atividade ou acontecimento no presídio, de acordo com a percepção dos respondentes, possibilita a ressocialização.

Após a leitura exaustiva dos questionários preenchidos foram utilizadas metodologias diferentes de análise: para os itens objetivos, análise estatística, para as questões "abertas", utilizamos a análise de conteúdo, conjunto de técnicas de análise das comunicações. (BARDIN, 1979).

Segundo Barros e Lehfeld (1996, p. 70), a análise de conteúdo "[...] é atualmente utilizada para estudar e analisar material qualitativo, buscando-se melhor compreensão de uma comunicação ou discurso, de aprofundar suas características gramaticais às ideológicas e outras, além de extrair os aspectos mais relevantes".

A análise de conteúdo não tem modelo pronto: constrói-se através de um vaivém contínuo e tem que ser reinventada a cada momento, conforme Bardin (1979, p. 31). Para o tratamento dos dados da pesquisa passamos pelos três momentos previstos pela autora: a pré-análise, a exploração do material e o tratamento dos resultados: (inferência e interpretação).

Para este artigo selecionamos alguns aspectos relacionados à percepção da escola e a uma representação social que emergiu na análise dos dados coletados: a de "enquadramento", de que trataremos a seguir.

\section{Alguns resultados... Educação ou enquadramento?}

\subsection{A escola prisional}

A escola em uma unidade penitenciária funciona nos turnos matutino e vespertino. $\mathrm{O}$ horário de funcionamento é de $9 \mathrm{~h}$ às $12 \mathrm{~h}$ e de $13 \mathrm{~h}$ às $16 \mathrm{~h}$. Há um intervalo de uma hora para que os funcionários da escola possam almoçar. O tempo de aula é de 45 minutos e a grade de aulas é organizada em quatro tempos pela manhã e quatro tempos à tarde. Os alunos são retirados das 
galerias pelo agente penitenciário que, diariamente, recebe uma listagem com o nome e a galeria do aluno.

As aulas são ministradas na modalidade da Educação de Jovens e Adultos (EJA) com uma matriz específica para escolas em presídio. A matriz é anual e não semestral como a maior parte das redes escolares formais.

Há aulas para as séries iniciais, que vão da alfabetização até o quinto ano, e para as séries finais que vão do sexto ao nono ano do Ensino Fundamental.

Além do Ensino Fundamental, os colégios oferecem o Ensino Médio. Os alunos têm aulas de Português e Literatura, Matemática, História, Geografia, Língua Estrangeira, Química, Física, Educação Física, Arte, Sociologia e Filosofia. Durante a aula é oferecida uma merenda seca, ou seja, um suco com biscoito, um achocolatado com biscoito etc. Algumas escolas oferecem uma sala com computadores sem acesso à internet e que são usados para fazer trabalhos e consultas a alguns conteúdos multimídia previamente autorizados pela direção da Unidade Prisional.

Existe também uma biblioteca com acervo de livros de várias áreas de conhecimento. Algumas escolas são climatizadas com ar condicionado, o que torna o ambiente muito mais agradável. Isto constituiu um benefício correlato importante, com as médias de temperatura nos presídios ultrapassando, em determinadas épocas do ano, os $40^{\circ} \mathrm{C}$.

\subsection{Para que ir à escola?}

Encontramos três grandes motivações para a frequência à escola: a remição da pena, a possibilidade de um futuro melhor, através da preparação para o trabalho, e o alcance de alguns benefícios imediatos. Observemos cada uma delas.

Os entrevistados conhecem o benefício que a escola pode trazer na remição da pena. Verificamos que $91,25 \%$ dos sujeitos entrevistados concordam que a frequência à escola auxilia a remição da pena, demonstrando que a conversação sobre o assunto, estabelecida no interior do presídio, produz representação e conhecimento sobre a Lei nº 12.433/2011.

Quando perguntados se a escola forma para o mundo do trabalho a maioria dos sujeitos $(86,25 \%)$ concordou com esta assertiva. Observando a idade dos respondentes ao questionário, verificamos que, quanto mais jovens, maior a esperança de ressocialização. 
A escola em presídio poderia ter em seu currículo a formação para o trabalho, porém, para isto, seria necessário que as escolas tivessem a autorização para que se tornassem técnicas. A Educação de Jovens e Adultos em presídio não tem esta autorização. O espaço escolar também teria de ser modificado para oferecer esta demanda de cursos.

A terceira razão de frequência à escola foi o alcance de outros benefícios que não têm relação direta com a prática pedagógica, mas estão associados à mobilidade no interior do presídio, mudança da dieta ofertada, relacionamento com a família e possibilidades de mais interações sociais.

A escola no presídio se institucionaliza permitindo outras ações correlatas que são parte constituinte da representação que os sujeitos têm da escola: sair da galeria, comer um lanche melhor, escrever cartas para a família e encontrar com colegas de outras galerias.

Ao avaliar a escola, as expressões mais frequentes foram: "a escola muda a minha condição"; "a escola tem finalidade" (no sentido de dar objetivo à vida, tornando-se um antídoto contra a depressão, doença institucional do presídio); "sinto-me livre quando estou na escola".

\subsection{A prioridade da escola entre outras atividades}

A escola só "perde" para a visita familiar, na escala de importância atribuída pelos participantes da pesquisa. A visita da família ocorre duas vezes na semana e é o momento em que o aprisionados e encontra com amigos e parentes. $\mathrm{Na}$ visita é muito comum que a família leve um lanche diferenciado e sucos. O preso tem o direito deste benefício, desde que não tenha cometido nenhuma falta como brigar com um colega, desrespeitar um agente, usar entorpecente, ser apanhado com aparelho eletrônico etc.

O parlatório, ou seja, a visita íntima ocorre normalmente de quinze em quinze dias e é considerado um benefício para os que se comportam bem. Ao contrário da visita familiar, este benefício não é regularizado, ficando a cargo do diretor do presídio a sua concessão.

A visita familiar é feita no pátio de visitas, que é uma sala grande com bancos e mesas de alvenaria onde todos se olham e podem ser comunicar. As crianças podem correr por entre as mesas. Há banheiros para o uso da família e para o preso.

O parlatório é uma galeria cujas celas são usadas com a finalidade de encontro sexual. O preso coloca um lençol na porta de entrada da cela para ter privacidade, já que as grades são vazadas.

\subsection{0 "enquadramento"}


Uma representação social relacionada à escola surgiu com maior intensidade e frequência do que aquelas relacionadas à Educação propriamente dita; a do enquadramento.

O comportamento na escola, considerado aqui como um conjunto de atitudes e condutas que devem obedecer a normas e regras, foi abordado em uma série de questões apresentadas aos sujeitos da pesquisa.

É comum nas cadeias que os presos mais antigos (chamados de "cascudos") orientem os mais novos no sentido de que não haja atitudes que comprometam o grupo. Eles chamam isto de enquadramento. Nas escolas, algumas regras são estabelecidas pelo grupo, de forma que a instituição funcione muito bem. Um aluno para ir à escola deve estar, pelo menos, de banho tomado. Não pode exalar cheiro forte; deve estar preferencialmente barbeado. Pode até usar uma "roupa velha", mas a mesma deve estar limpa. Não é permitida qualquer espécie de exposição do órgão genital e por isto o uso de cuecas é obrigatório. Na escola é permitido que o aluno não fique o tempo todo com as mãos para trás, como ocorre normalmente em outras dependências do presídio, mas a cabeça não deve ficar levantada o tempo todo e principalmente se houver professora por perto. É proibido que olhe para a professora e faça qualquer comentário em relação à sua aparência física.

O "cascudo" orienta que, se o aluno está ali, deve cumprir as atividades e regras escolares porque há muitos querendo estudar e a oportunidade está sendo dada para aquele em questão. Há cadeias para presos de facção criminosa que inclusive têm um regimento interno de comportamento. Se um professor ou professora estiver passando pelo corredor da cadeia, qualquer preso que não esteja com camisa deve se retirar da entrada da galeria para não proporcionar constrangimento ao profissional que está transitando. O tempo todo há observação comportamental, das autoridades e dos prisioneiros entre si, para que o enquadramento ocorra sem desvio de regras.

Também estão incluídas normas referentes à assiduidade, pontualidade, cumprimento das tarefas estabelecidas pelo professor, cuidado e usos do material didático.

A participação do aluno na escola está profundamente relacionada ao enquadramento. Várias atitudes são distribuídas sob a lógica do enquadramento no presídio: a relação com a autoridade, a ausência de manifestação de desejos e/ou interesses individuais em público e uma 


\section{Dialogia}

OLIVEIRA, Eloiza da Silva Gomes de; MELO, Ronaldo Silva. Representações sociais da ressocialização através da Educação: a prisão pode constituir-se em espaço educativo?

espécie de código de comportamento que signifique menos conflito e repressão das autoridades penitenciárias.

A tabela que se segue apresenta o quadro geral do "enquadramento" no ambiente escolar, como descrito pelos presos entrevistados. Observa-se que o enquadramento, como estabelecido pelos "cascudos", mais velhos no sistema penitenciário, constitui um conhecimento compartilhado através da conversação e caracteriza a representação do comportamento a ser exercido durante o período do cárcere.

Desta maneira, podemos afirmar que o enquadramento é o saber fundamental para o cotidiano no cárcere, o que estabelece, pelo processo e pelo efeito, como a representação social mais viva e familiar dos presidiários.

Quadro 1 - Caracterização da representação social "enquadramento no ambiente escolar"

\begin{tabular}{|c|c|}
\hline COMO VOCÊ REPRESENTA O ENQUADRAMENTO? & F(\%) \\
\hline Indo à escola todos os dias & 96,25 \\
\hline Priorizando a escola nos dias de semana & 36,25 \\
\hline Fazendo as atividades propostas pelo professor & 93,75 \\
\hline O aluno deve participar de atividades que gosta & 57,50 \\
\hline É importante o aluno escolher a aula que quer ter & 11,25 \\
\hline Não destruir o material didático fornecido & 93,75 \\
\hline Não trazer conflitos da galeria para a escola & 95 \\
\hline O aluno pode solicitar material sempre que quiser & 56,25 \\
\hline O aluno tem que comprovar que precisa de material & 72,5 \\
\hline O aluno tem obrigação de chegar na hora & 93,75 \\
\hline Na falta do professor, o aluno pode ir onde quiser & 10 \\
\hline O aluno pode ir ao banheiro quando quiser & 13,75 \\
\hline
\end{tabular}

Fonte: Análise dos dados da pesquisa realizada.

Concluímos este tópico apresentando a síntese da avaliação da escola prisional feita pelos entrevistados na pesquisa.

Quadro 2 - A avaliação da escola prisional pelos alunos

AVALIAÇÃO ATRIBUÍDA À ESCOLA PRISIONAL

\begin{tabular}{|l|c|c|c|c|c|c|c|}
\hline & \multicolumn{2}{|c|}{0 a 4} & \multicolumn{2}{|c|}{5 a 7} & \multicolumn{2}{|c|}{8 a 10} & Não \\
\cline { 1 - 5 } & $\mathrm{S}$ & $\mathrm{F}(\%)$ & $\mathrm{S}$ & $\mathrm{F}(\%)$ & $\mathrm{S}$ & $\mathrm{F}(\%)$ & opinou \\
\hline
\end{tabular}




\begin{tabular}{|l|c|c|c|c|c|c|c|}
\hline Qualidade do ensino & 01 & 1,25 & 13 & 16,25 & 65 & $\begin{array}{c}81,2 \\
5\end{array}$ & 01 \\
\hline Qualidade dos professores & - & - & 05 & 6,25 & 74 & 92,5 & 01 \\
\hline Qualidade do material didático & 08 & 10 & 25 & 31,25 & 42 & 52,5 & 05 \\
\hline $\begin{array}{l}\text { Qualidade das instalações físicas da } \\
\text { escola }\end{array}$ & 18 & 22,5 & 30 & 37,5 & 31 & $\begin{array}{c}38,7 \\
5\end{array}$ & 01 \\
\hline
\end{tabular}

Fonte: Análise dos dados da pesquisa realizada.

A escola no presídio é uma atividade recente na história brasileira, não desenvolve atividades profissionalizantes, é limitada por motivos de segurança e tem que se adequar ao "enquadramento" geral do presídio. Entretanto foi bem avaliada pelos estudantes, permitiu benefícios correlatos que constituíram uma vida melhor intramuros e possibilitou, principalmente através do ensino da língua, que se comunicassem com o mundo externo à prisão.

Quando foram apresentados os dados referentes ao enquadramento dos alunos no ambiente escolar, percebe-se que na escola fica, ou, consegue estudar, quem está em consonância com as regras estabelecidas. Quando perguntados sobre a nota para o seu próprio enquadramento e para o enquadramento do colega, o resultado obtido foi, respectivamente, $88,75 \%$ e $70 \%$ para "Ótimo Enquadramento". Isto constitui mais um dos marcadores da importância da representação social do enquadramento no universo prisional.

\section{Considerações finais... para continuar refletindo}

Utilizamos a expressão "para continuar refletindo" indicando quanto são frágeis e perecíveis as conclusões elaboradas a partir de pesquisas realizadas em ambientes prisionais.

Objetivamos neste artigo, com base nos estudo das representações sociais, forma de conhecimento reconhecida, embora polemizada, verificar a importância da educação como "catalizadora" do processo de ressocialização.

Verificamos que a educação oferecida pela rede escolar prisional, embora marcada de dificuldades e incompletudes, ainda é vista, principalmente pelos mais jovens, como favorecendo uma melhor condição de vida no retorno ao ambiente social externo à prisão.

$\mathrm{Na}$ análise dos dados obtidos, no entanto, a representação social do "enquadramento" superou a da educação escolar ressocializadora e redentora, constituindo um cenário, para nós, inesperado. 
A família ainda apareceu como a principal força na direção de ressocializar o presidiário seguido da escola e da religião, extremamente ligada à estrutura da própria penitenciária.

Ao pensar a educação em um espaço tão peculiar e difícil como a prisão, três questões nos parecem essenciais:

- A construção de uma concepção de educação prisional não como benesse, mas como direito cidadão. De Maeyer, especialista em pesquisa da UNESCO, declara que, segundo a Comunidade Internacional,“(...) a educação é um direito de todos. Considerar a educação na prisão como privilégio está fora dequestão. A prisão é a perda do direito de mobilidade, não dos direitos de dignidade, respeito e educação.”(2006, p. 21).

- Acreditar na educação como ferramenta de transformação do ser humano, como instrumento de reflexãopara a mudança de atitudes e valores capazes de assegurar um mundo melhor para todos, que deve ser nãoapenas uma utopia, mas uma meta a ser atingida. Isso implica investimento nos espaços educativos situados em ambiente prisional, feito não apenas através do aprimoramento dos recursos materiais, mas do reconhecimento da necessidade de uma "pedagogia específica" e de profissionais habilitados e concursados em quantidade suficiente, com garantia deformação inicial e continuada. Não só para educadores, mas para todos que direta ou indiretamente atuamno atendimento a esses sujeitos. (SILVA, 2010, p. 29).

- Pensar em uma verdadeira escola de ressocialização e isto significa voltar-se mais para a realidade do mundo de fora da prisão. Esta escola não pode ser representada como derivada no próprio enquadramento dos presidiários, mas atuarmais para o mundo do trabalho e promover a constituição de redes de apoio no ambiente "extramuros prisionais". A família do presidiário deve também ser objeto da ação educacional se quisermos efetivamente constituir processos de ressocialização.

O retorno ao convívio social após o encarceramento é uma mudança tão drástica quanto a entrada na prisão, pois "a primeira coisa a se perceber [...] é que tudo o que conhecêramos já não existe mais. Restam apenas cacos partidos de lembranças na memória. Inúteis para a gravidade das atuações necessárias no presente” (MENDES, 2006, p. 3-4). 


\section{Dialogia}

OLIVEIRA, Eloiza da Silva Gomes de, MELO, Ronaldo Silva. Representações sociais da ressocialização através da Educação: a prisão pode constituir-se em espaço educativo?

É necessário o distanciamento dos “enquadramentos" prisionais e o retorno a práticas sociais que, muitas vezes, provocaram o encarceramento. Estará a educação realizada em ambientes prisionais que oferecemos hoje realmente preocupada com esse retorno?

\section{Referências}

ABRIC, Jean-Claude. A abordagem estrutural das representações sociais. In MOREIRA, Antonia S. P. e OLIVEIRA, Denise C. (Orgs.). Estudos interdisciplinares de representação social. Goiânia: AB, 1998.

BARDIN, L. Análise de conteúdo. Lisboa: Edições 70, 1979.

BARROS, A. de J. P.; LEHFELD, N. A. de S. Projeto de pesquisa: propostas metodológicas. Petrópolis: Vozes, 1996.

BRASIL. Constituição da República Federativa do Brasil de 1988. Brasília, Presidência da República, Casa Civil. Disponível em:

http://www.planalto.gov.br/ccivil 03/Constituicao/Constituicao.htm. Acesso em: 20 fev. 2020.

BRASIL. Lei N N $^{\circ} .210$, de 11 de julho de 1984. Institui a Lei de Execução Penal. Brasília, Presidência da República, Casa Civil. Disponível em:

http://www.planalto.gov.br/ccivil 03/leis/17210.htm. Acesso em: 20 fev. 2020.

BRASIL. Lei No 12.433, de 29 de junho de 2011. Altera a Lei no 7.210, de 11 de julho de 1984 (Lei de Execução Penal), para dispor sobre a remição de parte do tempo de execução da pena por estudo ou por trabalho. Presidência da República, Casa Civil. Disponível em:http://www.planalto.gov.br/ccivil 03/ ato2011-2014/2011/lei/112433.htm. Acesso em: 20 fev. 2020.

BRASIL. Levantamento Nacional de Informações Penitenciárias / atualização junho de 2017. SILVA, Marcos Vinícius Moura (Org.). Brasília, Ministério da Justiça e Segurança Pública, Departamento Penitenciário Nacional, 2019. Disponível em:

http://depen.gov.br/DEPEN/depen/sisdepen/infopen/relatorios-sinteticos/infopen-jun-2017rev-12072019-0721.pdf. Acesso em: 20 fev. 2020.

DE MAEYER, Marc. Na prisão existe a perspectiva da Educação ao longo da Vida? In Revista de Educação de Jovens e Adultos, No 19. Brasília: RAAAB, UNESCO, Governo Japonês, jul. 2006, p. 18 $-37$.

DESCHAMPS, J. C. e MOLINER, P. Identidade em Psicologia Social.Petrópolis: Vozes, 2009. JODELET, D. Représentations sociales: phénomènes, concept et théorie. In:MOSCOVICI, S. (Ed.). Psychologie sociale. Paris: Presses Universitaires deFrance, 1984.

MENDES, Luiz. Como nasceu a ideia deste guia. In: SÃO PAULO. Dicas: 


\section{Dialogia}

OLIVEIRA, Eloiza da Silva Gomes de; MELO, Ronaldo Silva. Representações sociais da ressocialização através da Educação: a prisão pode constituir-se em espaço educativo?

O guia que você precisa para ficar livre de vez: São Paulo: FUNAP, DRS/SAP, 2006.

Disponível em:http://www.reintegracaosocial.sp.gov.br/db/crsc-

kyu/archives/a6c6f3852dd2b3aa7e04ce627434f478.pdf. Acesso em 27 fev. 2020.

MOSCOVICI, S. A representação social da psicanálise. Rio de Janeiro: Zahar,1978.

MOSCOVICI, Serge. Notes towards a description of Social Representations. European Journal of Social Psychology, 18, 1988, p. 211-250.

Recebido em: 28 fev. 2020 / Aprovado em: 18 mar. 2020

Cite como (ABNT NBR 6023:2018)

OLIVEIRA, Eloiza da Silva Gomes de; MELO, Ronaldo Silva. Representações sociais da ressocialização através da Educação: A Prisão pode constituir-se em espaço educativo? Dialogia, São Paulo, n. 34, p. 153-166, jan./abr. 2020. Disponível em:

https://doi.org/10.5585/Dialogia.N34.16702. 